\title{
Adsorption Kinetics of Arsenic (V) on Nanoscale Zero-Valent Iron Supported by Activated Carbon
}

\author{
Huijie Zhu ${ }^{1,2, \dagger}$, Mingyan Shi ${ }^{2,+}$, Xiuji Zhang ${ }^{1}$, Bo Liu ${ }^{3, * \mathbb{D}}$ and Dahu Yao ${ }^{4}$ \\ 1 Henan International Joint Laboratory of New Civil Engineering Structure, College of Civil Engineering, \\ Luoyang Institute of Science and Technology, Luoyang 471023, China; huijiezhu@lit.edu.cn (H.Z.); \\ zhangxiuji@lit.edu.cn (X.Z.) \\ 2 College of Civil Engineering, Guangzhou University, Guangzhou 510006, China; shmygz@gzhu.edu.cn \\ 3 Laboratory of Functional Molecular and Materials, School of Physics and Optoelectronic Engineering, \\ Shandong University of Technology, Zibo 255000, China \\ 4 School of Chemical Engineering \& Pharmaceutics, Henan University of Science \& Technology, \\ Luoyang 471003, China; dh.yao@haust.edu.cn \\ * Correspondence: liub@sdut.edu.cn; Tel.: +86-533-2783909 \\ + These authors contributed equally to the work.
}

Received: 24 August 2020; Accepted: 5 September 2020; Published: 9 September 2020

\begin{abstract}
The presence of arsenic (As) in drinking water is of serious concern due to its negative impact on human health. This work reports on the kinetics of nanoscale zero-valent iron $\left(\mathrm{Fe}^{0}\right)$ supported by activated carbon (NZVI/AC) for the removal of As (V) species from aqueous solutions. To better understand the factors affecting this process, we investigated the effects of various experimental parameters including initial As (V) concentration, adsorbent dosage, $\mathrm{pH}$, temperature, and coexisting ions on the adsorption kinetics using a batch-adsorption method. The optimum conditions for As (V) removal by NZVI/AC were found to be: $318 \mathrm{~K}$, pH 3.5, an adsorbent dosage of $1.5 \mathrm{~g} / \mathrm{L}$, and an equilibrium time of $72 \mathrm{~h}$. A greater mass of NZVI/AC, lower concentration of As (V) and lower $\mathrm{pH}$ positively promoted adsorption kinetics. The presence of phosphate $\left(\mathrm{PO}_{4}^{3-}\right)$ and silicate $\left(\mathrm{SiO}_{4}^{2-}\right)$ markedly inhibited As (V) removal kinetics. However, in the presence of $4.5 \mathrm{~g} / \mathrm{L} \mathrm{NZVI} / \mathrm{AC}, \geq 99.9 \%$ of As $(\mathrm{V})$ was removed from raw groundwater.
\end{abstract}

Keywords: nanoscale zero-valent iron supported on activated carbon (NZVI/AC); arsenate (As(V)); adsorption kinetics; intra-particle diffusion

\section{Introduction}

Arsenic (As) is associated with serious environmental concerns because of its noted negative impact on human health ranging from acute lethality to carcinogenicity and chronic health effects [1]. Drinking water is one of the major sources of As exposure in the general population, especially in some developing countries, such as Bangladesh, China, and Vietnam. Among various As removal techniques, the zero-valent iron $\left(\mathrm{Fe}^{0}\right)$ adsorption method has been widely adopted because it is simple and cost-effective [2-10].

Nanoscale $\mathrm{Fe}^{0}$ (NZVI) is a very promising adsorbent for As elimination from drinking water since it possesses a high As adsorption capacity and a large specific surface area. Moreover, NZVI has an As removal mechanism similar to ZVI [11-13]. However, the direct application of NZVI in water cleaning systems might result in NZVI losses and secondary contamination of the drinking water. Instead, NZVI supported by activated carbon (NZVI/AC) can safely and effectively remove arsenic due to its great porosity, low cost, and mechanical stability [12,14].

Adsorption kinetics analysis typically provides data on how experimental conditions affect the adsorption speed and rate as a function of time [15]. The solute uptake rate, needed to determine 
the residence time, is required to assess the adsorption reaction completion. Moreover, the scaling-up of the adsorption equipment also requires kinetic data [16,17].

The kinetics of the removal of As from aqueous solutions by ZVI media has been the subject of several recent investigations. Lackovic et al. [18] studied the As removal kinetics from water in terms of removal efficiencies, but this type of kinetic information is linked to a concrete case and therefore not useful for determining general experimental conditions. The kinetics of $\mathrm{As}(\mathrm{V})$ removal by ZVI over a one-year period ranged between first- and zeroth-order regarding the aqueous $\mathrm{As}(\mathrm{V})$ concentration, and the reaction rate was dependent on the aqueous $\mathrm{As}(\mathrm{V})$ concentration and availability of adsorption sites. Kanel et al. [19] used a first-order model to describe As(V) removal by NZVI kinetics and illustrated iron's capacity for As (V) removal using a Langmuir adsorption model. However, there has been no systematic study on the kinetics of $\mathrm{As}(\mathrm{V})$ elimination by nanoscale absorbent materials supported onto carriers. NZVI/AC can avoid the aggregation of NZVI, so it is easy to recover and reuse in engineering. Therefore, an in-depth understanding of its dynamics would help in accelerating the application of nanomaterials in the field of environmental remediation. However, the carrier also significantly increases its steric hindrance and decreases reaction opportunities, so it is necessary to organically study its kinetics, which are affected by many common factors.

We have previously [12] prepared activated carbon (AC)-supported NZVI by saturating AC with $\mathrm{Fe}^{2+/ 3+}$ followed by in-situ reduction to $\mathrm{Fe}^{0}$. In the present study, we investigated its characteristics, including the effects of adsorbent mass, initial $\mathrm{As}(\mathrm{V})$ concentration, $\mathrm{pH}$ of the solution, coexisting ions, and temperature on the reaction kinetics of $\mathrm{As}(\mathrm{V})$ removal, in a batch reaction system. The above parameters showed important effects on the dynamics of the adsorption system. The results are explained in terms of the intra-particle diffusion mechanisms. Furthermore, the kinetic model fitting the experimental data was used to analyze the performance of the NZVI/AC adsorption system in the removal of $\mathrm{As}(\mathrm{V})$ from raw (untreated) groundwater.

\section{Experimental Section}

\subsection{Synthesis and Characterization of NZVI/AC}

The NZVI/AC was synthesized as described elsewhere [12]. The morphology of the resulting samples was characterized by scanning electron microscopy (SEM) using the Hitachi SU 8220 instrument (SU8200, Hitachi, Tokyo, Japan). The surface area and porosity were calculated using the Brunauer-Emmett-Teller (BET) method from data including the $\mathrm{N}_{2}$ adsorption/desorption that were collected using a PMI BET-201A (Porous Materials Inc., Ithaca, NY, USA). The iron content was analyzed as described elsewhere [12]. Briefly, $0.1 \mathrm{~g}$ of adsorbent was added to $30 \mathrm{~mL}$ of $7 \mathrm{M} \mathrm{HCl}$. The mixture was then placed into a water bath at $25^{\circ} \mathrm{C}$ for $2 \mathrm{~h}$, after which the temperature was slowly increased (over the next $20 \mathrm{~min}$ ) to $90^{\circ} \mathrm{C}$. After the formation of a solid product, the supernatant was filtered and subjected to spectrophotometric analysis using an inductively coupled plasma optical emission spectrophotometer (ICP-OES; Varian 700-ES, Varian Inc. Scientific Instruments, Palo Alto, CA, USA).

\subsection{Methods of Adsorption Kinetics}

The effect of experimental parameters, including initial $\mathrm{As}(\mathrm{V})$ concentration $(0.5,1,2$, and $4 \mathrm{mg} / \mathrm{L})$, adsorbent dosage $(0.5,1.0,1.5$, and $2.0 \mathrm{~g} / \mathrm{L}), \mathrm{pH}(3.5,6.5$, and 9.5), single and multiple coexisting ions (phosphate $\left(\mathrm{PO}_{4}^{3-}\right)$ and silicate $\left.\left(\mathrm{SiO}_{4}^{2-}\right)\right)$ at a ratio to $\mathrm{As}(\mathrm{V})$ of $10: 1$, and temperature $(298,308$, and $318 \mathrm{~K})$, on the $\mathrm{As}(\mathrm{V})$ adsorption, was studied in conical flasks. For this purpose, $500 \mathrm{~mL}$ of an $\mathrm{As}(\mathrm{V})$ solution $(2 \mathrm{mg} / \mathrm{L})$ was added into each flask and the $\mathrm{pH}$ was adjusted to 6.5 using $\mathrm{NaOH}$ or $\mathrm{HCl}$. The resulting mixture was shaken for $72 \mathrm{~h}$ at $298 \mathrm{~K}$. Aliquots $(5 \mathrm{~mL})$ of the supernatants were filtered over a $0.45 \mu \mathrm{m}$ Millipore filter. The $\mathrm{As}(\mathrm{V})$ content was then analyzed by hydride generation atomic fluorescence spectrophotometry (HG-AFS) using an AFS-2202E instrument (Haiguang Corporation, Beijing, China). The $\mathrm{As}(\mathrm{V})$ detection limit and analytic regression coefficient $\left(\mathrm{R}^{2}\right)$ were $0.1 \mu \mathrm{g} / \mathrm{L}$ and $>0.9990$, respectively. 
The multiple coexisting ions test was performed in the same way as the single coexisting ions test except for the presence of coexisting ions in the solution.

The residual concentration in the adsorbent $\left(q_{t}, \mathrm{mg} / \mathrm{g}\right)$ was calculated as follows

$$
q_{t}=\frac{V\left(C_{0}-C_{t}\right)}{W_{s}}
$$

where $C_{0}$ and $C_{t}$ are initial $\mathrm{As}(\mathrm{V})$ concentration (in $\mathrm{mg} / \mathrm{L}$ ) and the concentration of $\mathrm{As}(\mathrm{V})$ at time $t$, respectively; $V$ is the solution volume (in $\mathrm{L}$ ) and $W_{S}$ is the adsorbent weight $(\mathrm{g})$. The percentage of removed $\mathrm{As}(\mathrm{V})(\mathrm{R} \%)$ was calculated by the equation shown below:

$$
R(\%)=\frac{C_{0}-C_{t}}{C_{0}} \times 100
$$

\subsection{Models}

An intraparticle diffusion model [20] was applied to compute the As(V) adsorption kinetics in this study according to the equation

$$
q_{t}=k_{i d} t^{0.5}
$$

where $k_{i d}$ is the original rate of intraparticular diffusion $\left(\mathrm{mg} \cdot \mathrm{g}^{-1} \cdot \mathrm{h}^{-0.5}\right) ; q_{t}(\mathrm{mg} / \mathrm{g})$ is the quantity of As(V) adsorbed at time $t$.

\subsection{The Qualitative Parameters of the Simulation and Raw Groundwater}

The chemical composition of the simulation water included the specific ions context mentioned dissolved in deionized water.

To test the performance of our synthesized NZVI/AC in the removal of As(V) from raw groundwater, we used water from a pump well in Tumed Left Banner, Hohhot City, Inner Mongolia, a village affected by arsenicosis. The quality parameters of the raw water are listed in Table 1 . The depth of the groundwater of the pump well was $6 \mathrm{~m}$; water temperature: $13{ }^{\circ} \mathrm{C}$; total hardness: $49.0 \mathrm{mg} / \mathrm{L}$.

Table 1. The raw ground-water quality parameters.

\begin{tabular}{ccccccccccc}
\hline $\begin{array}{c}\mathrm{As} \\
(\mathrm{mg} / \mathrm{L})\end{array}$ & $\mathbf{p H}$ & $\begin{array}{c}\mathrm{TOC} \\
(\mathrm{mg} / \mathrm{L})\end{array}$ & $\begin{array}{c}\mathrm{NH}_{3}-\mathrm{N} \\
(\mathbf{m g} / \mathrm{L})\end{array}$ & $\begin{array}{c}\mathrm{Fe} \\
(\mathrm{mg} / \mathrm{L})\end{array}$ & $\begin{array}{c}\mathrm{SO}_{4}{ }^{2-} \\
(\mathrm{mg} / \mathrm{L})\end{array}$ & $\begin{array}{c}\mathrm{Cl}^{-} \\
(\mathrm{mg} / \mathrm{L})\end{array}$ & $\begin{array}{c}\mathrm{F}^{-} \\
(\mathrm{mg} / \mathrm{L})\end{array}$ & $\begin{array}{c}\mathrm{Na}^{+} \\
(\mathbf{m g} / \mathrm{L})\end{array}$ & $\begin{array}{c}\mathrm{K}^{+} \\
(\mathbf{m g} / \mathrm{L})\end{array}$ & $\begin{array}{c}\mathrm{Al}^{3+} \\
(\mathbf{m g} / \mathrm{L})\end{array}$ \\
\hline 1.971 & 7.58 & 12.3 & 0.475 & 4.6 & 349 & 174 & 1.62 & 137 & 3.9 & 1.04 \\
\hline
\end{tabular}

\section{Results}

\subsection{Adsorbent Characterization}

The SEM micrographs of NZVI/AC demonstrated that AC-supported NZVI particles of $\sim 20 \mathrm{~nm}$ thickness were shaped like flakes (Figure 1). In comparison, clusters of round-shaped particle aggregates were formed by NZVI, which was synthesized in solution with a diameter $<100 \mathrm{~nm}[7,11]$. Most of the NZVI particles were located in the AC cracks and pores, which is an excellent benefit for future usage of this material for water treatment since it minimizes $\mathrm{Fe}^{0}$ nano-particle loss.

The Fe content of the NZVI/AC was $8.2 \%$, whereas Fe was completely absent from unmodified AC. The total pore volume and BET surface area of the AC were $0.45 \mathrm{~cm}^{3} / \mathrm{g}$ and $821.7 \mathrm{~m}^{2} / \mathrm{g}$, respectively, which decreased to $0.078 \mathrm{~cm}^{3} / \mathrm{g}$ and $69.4 \mathrm{~m}^{2} / \mathrm{g}$, respectively, upon loading with NZVI, illustrating the remarkable changes to the porous structure of the AC upon loading with NZVI. These results were similar to those reported by Tan who studied the removal behavior of Se(IV)/Se(VI) from aqueous solution using biochar-and activated carbon-supported zerovalent iron, respectively [11]. 


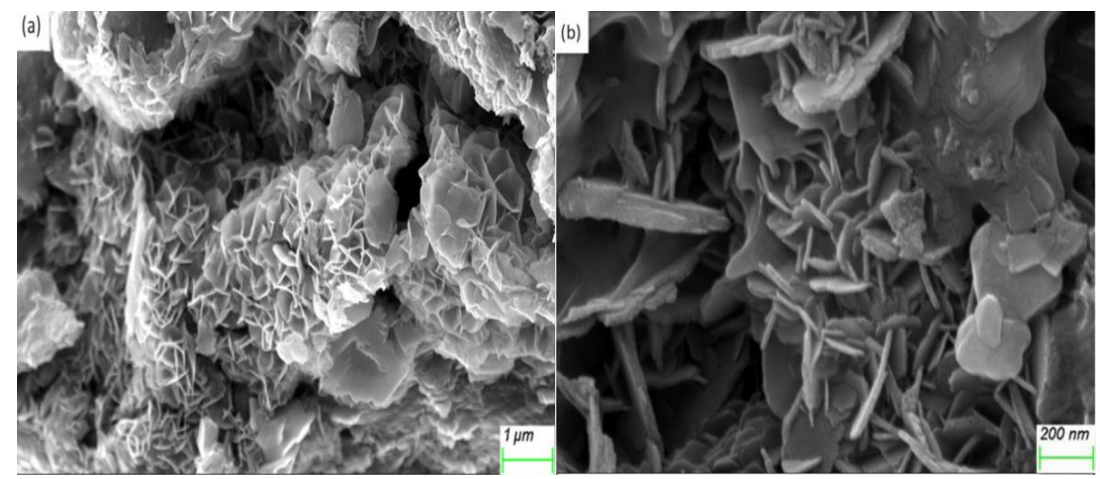

Figure 1. Scanning electron microscopy (SEM) images of the activated-charcoal (AC)—supported nanoscale zero-valent iron (NZVI) particles. (a) image at low magnification; (b) image at high magnification.

\subsection{Adsorption Kinetics of $A s(V)$ on NZVI/AC}

\subsubsection{Effect of the Initial $\mathrm{As}(\mathrm{V})$ Concentration on Adsorption Kinetics}

The effect of the initial $\mathrm{As}(\mathrm{V})$ concentration on its adsorption on NZVI/AC was studied by incubation for $72 \mathrm{~h}$ at $\mathrm{pH}$ 6.5. When the initial $\mathrm{As}(\mathrm{V})$ concentration was changed from 0.5 to $4.0 \mathrm{mg} / \mathrm{L}$ the amount of removed $\mathrm{As}(\mathrm{V})$ decreased from 99.9 to $62.4 \%$ (Figure $2 \mathrm{a}$ ) and the $q_{t}$ adsorption increased from 0.500 to $2.497 \mathrm{mg} / \mathrm{g}$ (Figure $2 \mathrm{~b}$ ). Thus, the removal of the $\mathrm{As}(\mathrm{V})$ was dependent on the original concentration. The same trend was observed for the adsorption of $\mathrm{As}(\mathrm{V})$ onto untreated powdered eggshell [21] and of $\mathrm{Cr}(\mathrm{VI})$ onto activated carbon stemming from wood apple shell [22].

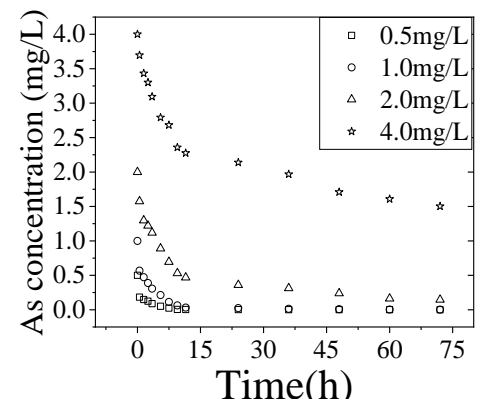

(a)

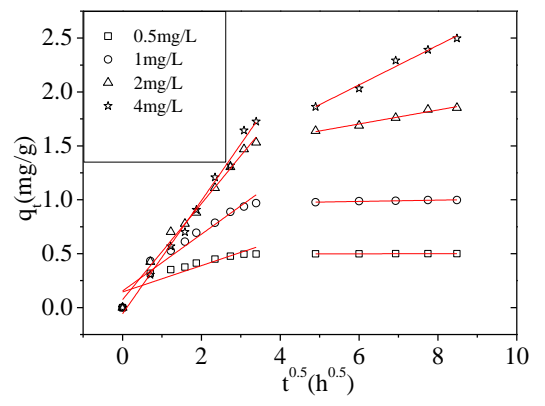

(b)

Figure 2. Adsorption kinetics of $\mathrm{As}(\mathrm{V})$ on NZVI/AC. (a) Effect of the initial concentration of $\mathrm{As}(\mathrm{V})$ on its adsorption on NZVI/AC as a function of incubation time. (b) Effect of the initial concentration of As(V) on $\mathrm{q}_{\mathrm{t}}$ and intraparticle diffusion model fit for the $\mathrm{As}(\mathrm{V})$ removal at different initial $\mathrm{As}(\mathrm{V})$ concentrations by NZVI/AC. Conditions: $\mathrm{pH}=6.5,150 \mathrm{rpm}, 20 \times 40$ mesh particle size, adsorbent dosage $=1.5 \mathrm{~g} / \mathrm{L}$, $t=72 \mathrm{~h}, \mathrm{~T}=298 \mathrm{~K}, \mathrm{C}_{0}=0.5,1.0,2.0$, and $4.0 \mathrm{mg} / \mathrm{L}$.

The fast, initial adsorption gradually slowed down (Figure 2a). The adsorption equilibrium, reached within $72 \mathrm{~h}$, was considered to be enough for the significant removal of $\mathrm{As}(\mathrm{V})$ and therefore $72 \mathrm{~h}$ was used for all the further experiments. Similar phenomena were seen with other initial concentrations.

To design the adsorption treatment systems, many models for liquid-phase adsorption were used to analyze the adsorption kinetic data but only the intraparticle diffusion model fitted well $\left(R^{2}>0.9\right)$ in this study.

Weber and Morris have illustrated that intraparticle diffusion is the rate-limiting factor in an adsorption system and the mass of the adsorbed substrate changes linearly as a function of the square root of time $\left(t^{1 / 2}\right)$. These data were then used to calculate the speeds of adsorption [20]. When $q_{t}$ was plotted as a function of $t^{1 / 2}$, a linear relationship was seen in two separate stages (Figure 2b). Therefore, Equation (1) was applied to these two stages separately. The first linear section of this graph 
corresponded with the adsorption on the NZVI located inside the macropores while the second very likely corresponded with the diffusion of $\mathrm{As}(\mathrm{V})$ into micro- and/or mesopores. Adsorption of $\mathrm{As}(\mathrm{V})$ on the NZVI particles located inside the AC macropores or channels was quick, while their diffusion into micro- and mesopores was slow because most of these pores were blocked. Apart from the pore diffusion process, the corrosion of the ZVI surface, adsorption, and diffusion in the corrosion layers were also involved.

Two different $k_{i d}$ values were calculated from the slopes of the two linear stages of the plots. The correlation coefficient $\left(R^{2}\right)$ values of the first and second stages of the plots at each $C_{0}$ are listed in Table 2. All $k_{i d}$ values of the 1st stage were higher than those of the 2nd stage, indicating a higher reaction velocity of the 1 st stage compared with the 2 nd stage, which was consistent with Figure $2 b$. Similar phenomena were found for adsorption of acid dye adsorption on activated palm ash [23] and $\mathrm{Cu}(\mathrm{II})$ and $\mathrm{Cd}(\mathrm{II})$ on rice/modified rice husk [24]. However, the rate constants, calculated $q_{e}$ values and were closer to the experimental $q_{e}$ values for the pseudo-second-order (PSO) model than for the pseudo-first-order model when using nanoscale zero-valent iron impregnated with clays adsorption and degradation of $\mathrm{Zn}^{2+}$ and $\mathrm{Cu}^{2+}$ from wastewaters. It can be concluded from the kinetic parameters that $\mathrm{Cr}(\mathrm{VI})$ removal by $\mathrm{nZVI} / \mathrm{BC}$ is controlled by a chemical process, which indicates that adsorption/coprecipitation and reduction occurred during $\mathrm{Cr}(\mathrm{VI})$ removal. This is due to the fact that the clay has a too-low porosity rate [6]. Jingge Shang found that the PSO model provided a better fit with the kinetic data for removal of $\mathrm{Cr}(\mathrm{VI})$ by nanoscale zerovalent iron particles supported on herb-residue biochar. Therefore, the kinetic parameters are controlled by a chemical process, which indicates that adsorption/coprecipitation and reduction occurred during $\mathrm{Cr}(\mathrm{VI})$ removal [5].

Table 2. Rate constants for the kinetic model of the adsorption of $\mathrm{As}(\mathrm{V})$ on NZVI/AC at different initial As $(\mathrm{V})$ concentrations.

\begin{tabular}{ccccc}
\hline \multirow{2}{*}{ Parameter } & \multicolumn{3}{c}{ Weber-Morris Diffusion } \\
\cline { 2 - 5 } & \multicolumn{3}{c}{ 1st Step } & \multicolumn{2}{c}{ 2nd Step } \\
\hline $\boldsymbol{C}_{\mathbf{0}}(\mathbf{m g} / \mathrm{L})$ & $\boldsymbol{k}_{\boldsymbol{i d \mathbf { 1 }}}$ & $\mathbf{R}^{\mathbf{2}}$ & $\boldsymbol{k}_{\boldsymbol{i d} \mathbf{2}}$ & $\mathbf{R}^{\mathbf{2}}$ \\
\hline 0.5 & 0.1224 & 0.7636 & 0.0004 & 0.9774 \\
1.0 & 0.2632 & 0.9293 & 0.0060 & 0.9341 \\
2.0 & 0.4449 & 0.9900 & 0.0648 & 0.9673 \\
4.0 & 0.5251 & 0.9913 & 0.1835 & 0.9769 \\
\hline
\end{tabular}

\subsubsection{Effect of the Adsorbent Dosage on the Adsorption Kinetics}

The As(V) removal rate increased from $\sim 63.6$ to $\sim 100 \%$ when the NZVI/AC dose was increased from 0.5 to $2.0 \mathrm{~g} / \mathrm{L}$ (Figure 3). However, the amount of adsorbed As(V) and the $k_{i d 1}$ values decreased from 2.545 to $0.9990 \mathrm{mg} / \mathrm{g}$ and 0.5515 to $0.2482 \mathrm{mg} \cdot \mathrm{g}^{-1} \cdot \mathrm{h}^{-0.5}$, respectively (Table 3). This was due to the fact that as the mass of the adsorbent increased, the corresponding adsorption rate decreased because of the lower adsorption capacity of the adsorbent $[19,23]$.

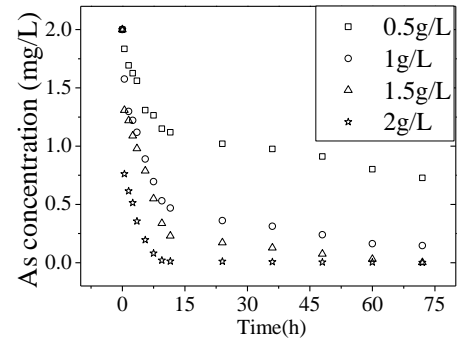

(a)

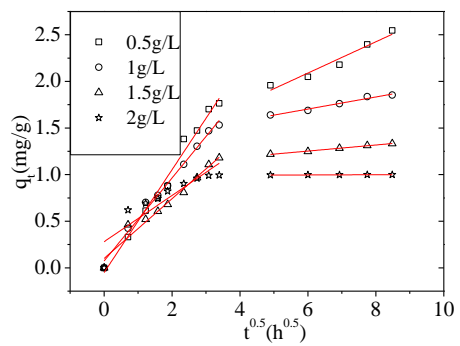

(b)

Figure 3. The $\mathrm{As}(\mathrm{V})$ removal rate as function of adsorbent concentration. (a) Effect of varying the adsorbent concentration on as function of time. (b) Intraparticle diffusion model fit for the As(V) removal rate by NZVI/AC at various adsorbent dosages (conditions: $C_{0}=2.0 \mathrm{mg} / \mathrm{L}, \mathrm{pH}=6.5,150 \mathrm{rpm}, 20 \times 40$ mesh particle size, $t=72 \mathrm{~h}, \mathrm{~T}=298 \mathrm{~K}$, adsorbent dosage: $0.5-2.0 \mathrm{~g} / \mathrm{L}$ ). 
Table 3. Rate constants for the kinetic model of the adsorption of $\mathrm{As}(\mathrm{V})$ on $\mathrm{NZVI} / \mathrm{AC}$ at different adsorbent dosages.

\begin{tabular}{ccccc}
\hline \multirow{2}{*}{ Parameter } & \multicolumn{3}{c}{ Weber-Morris Diffusion } \\
\cline { 2 - 5 } & \multicolumn{3}{c}{ 1st Step } & \multicolumn{2}{c}{ 2nd Step } \\
\hline $\boldsymbol{C}_{\mathbf{0}}(\mathbf{m g} / \mathbf{L})$ & $k_{i d \mathbf{1}}$ & $\mathbf{R}^{\mathbf{2}}$ & $\boldsymbol{k}_{\boldsymbol{i d} \mathbf{2}}$ & $\mathbf{R}^{\mathbf{2}}$ \\
\hline 0.5 & 0.5515 & 0.9838 & 0.1677 & 0.9399 \\
1.0 & 0.4449 & 0.9900 & 0.0647 & 0.9672 \\
1.5 & 0.3203 & 0.9662 & 0.0326 & 0.9934 \\
2.0 & 0.2482 & 0.7790 & 0.0012 & 0.9234 \\
\hline
\end{tabular}

\subsubsection{Effect of $\mathrm{pH}$ on the Adsorption Kinetics}

Next, we tested the effect of the $\mathrm{pH}$ of the solution on the $\mathrm{As}(\mathrm{V})$ adsorption capacity of $\mathrm{NZVI} / \mathrm{AC}$. Our results showed that the removal rate of $\mathrm{As}(\mathrm{V})$ decreased with increasing $\mathrm{pH}$ value. The percent removal $(R \%)$ of $\mathrm{As}(\mathrm{V})$ by $\mathrm{NZVI} / \mathrm{AC}$ reduced from $99.99 \%$ to $92.7 \%$ and $41.3 \%$ as the $\mathrm{pH}$ increased from 3.5 to 6.5 and 9.5, respectively (Figure 4 ).

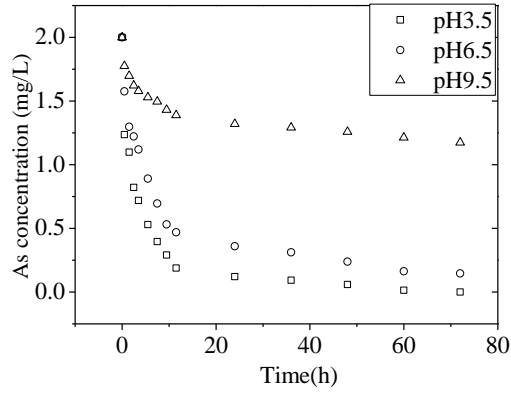

(a)

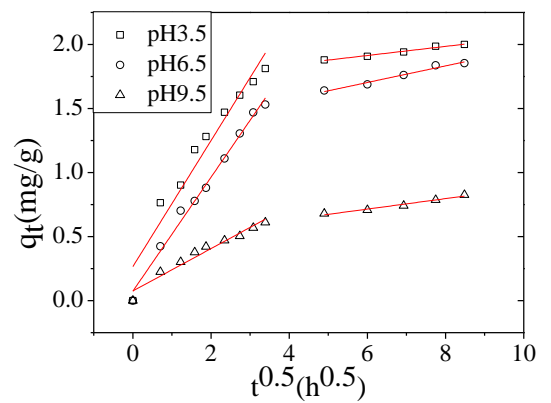

(b)

Figure 4. Effect of the $\mathrm{pH}$ on the $\mathrm{As}(\mathrm{V})$ removal rate. (a) Effect of the $\mathrm{pH}$ on the $\mathrm{As}(\mathrm{V})$ removal rate as a function of time. (b) Intraparticle diffusion model fit for the As (V) removal rate by NZVI/AC at different $\mathrm{pH}$ values (conditions: $C_{0}=2.0 \mathrm{mg} / \mathrm{L}, 150 \mathrm{rpm}, 20 \times 40$ mesh particle size, $t=72 \mathrm{~h}, \mathrm{~T}=298 \mathrm{~K}$, adsorbent dosage $=1.5 \mathrm{~g} / \mathrm{L}, \mathrm{pH}=3.5,6.5$, and 9.5).

The $\mathrm{pH}$ of the solution affects not only the speciation of heavy metals but also their ability to be removed using different types of functional groups and nanomaterials. The $\mathrm{pH}$ values will affect the ionization of acidic groups and the surface charges. Table 4 displays the values of calculated kinetic constants at $\mathrm{pH} 3.5,6.5$, and 9.5. All values of the correlation coefficients were $>0.9362$. The $k_{i d 1}$ values decreased with increasing $\mathrm{pH}$, indicating that the diffusion coefficients inside the particle pores decreased in the same $\mathrm{pH}$ range. As the $\mathrm{pH}$ increased from 3.5 to 6.5 and 9.5, the $k_{i d 1}$ value for the $\mathrm{As}(\mathrm{V})$ adsorption on NZVI/AC decreased by $10.1 \%$ and $73.4 \%$, respectively (Table 4 ).

Table 4. Rate constants for the adsorption kinetic model of $\mathrm{As}(\mathrm{V})$ on NZVI/AC at different $\mathrm{pH}$ values.

\begin{tabular}{ccccc}
\hline \multirow{2}{*}{ Parameter } & \multicolumn{4}{c}{ Weber-Morris Diffusion } \\
\cline { 2 - 5 } & \multicolumn{3}{c}{ 1st Step } & \multicolumn{2}{c}{ 2nd Step } \\
\hline pH & $\boldsymbol{k}_{\boldsymbol{i d \mathbf { 1 }}}$ & $\mathbf{R}^{\mathbf{2}}$ & $\boldsymbol{k}_{\text {id } \mathbf{2}}$ & $\mathbf{R}^{\mathbf{2}}$ \\
\hline 3.5 & 0.4921 & 0.9362 & 0.0355 & 0.9731 \\
6.5 & 0.4449 & 0.9899 & 0.0647 & 0.9673 \\
9.5 & 0.1654 & 0.9532 & 0.0409 & 0.9646 \\
\hline
\end{tabular}

Dissociation constants for the adsorption reactions performed at $\mathrm{pH}$ values of $3.5,6.5$, and 9.5 were equal to $\mathrm{pK}_{\mathrm{a} 1}=2.3, \mathrm{pK}_{\mathrm{a} 2}=6.8$, and $\mathrm{pK}_{\mathrm{a} 3}=11.6$ [24]. These differences occurred since, at these $\mathrm{pH}$ values 
$\mathrm{As}(\mathrm{V})$ exists as $\mathrm{H}_{2} \mathrm{AsO}_{4}{ }^{-}, \mathrm{HAsO}_{4}{ }^{2-}$, and $\mathrm{AsO}_{4}{ }^{3-}$ species, respectively. The $\mathrm{pH}$ of the zero-point charge $\left(\mathrm{pH}_{\mathrm{ZPC}}\right)$ of NZVI/AC is equal to 7.4. The adsorption of anionic species is most favorable at $\mathrm{pH}$ values below the $\mathrm{pH}_{\mathrm{ZPC}}$ because then the adsorbent surface is positively charged. As the $\mathrm{pH}$ of the solution increases, the adsorbent surface becomes less positive, which decreases its attraction toward anionic As-species. The steric hindrance of $\mathrm{H}_{2} \mathrm{AsO}_{4}{ }^{-}$is greater than that of $\mathrm{HAsO}_{4}{ }^{2-}$, which partially explains the lower $k_{i d 2(\mathrm{pH} 3.5)}$ value compared with $k_{i d 2(\mathrm{pH} 6.5)}$. Therefore, the adsorption of $\mathrm{As}(\mathrm{V})$ and its kinetics decreased significantly at higher $\mathrm{pH}$ values, which agrees with the previously reported literature on NZVI $[19,25,26]$.

\subsubsection{Effect of Temperature on Adsorption Kinetics}

The removal of the As $(\mathrm{V})$ from solution by NZVI/AC was studied at 298, 308, and $318 \mathrm{~K}$ to determine the adsorption thermodynamic parameters (Figure 5). The $q_{e}$ of NZVI/AC increased from 1.854 to $1.998 \mathrm{mg} / \mathrm{g}$ upon raising the temperature of the As(V) solution from 298 to $308 \mathrm{~K}$ (Table 5). Similar trends were observed for the aqueous phase adsorptions [23,27].

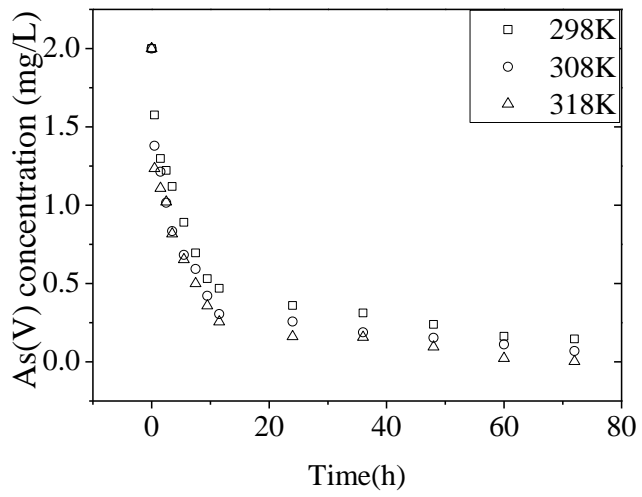

(a)

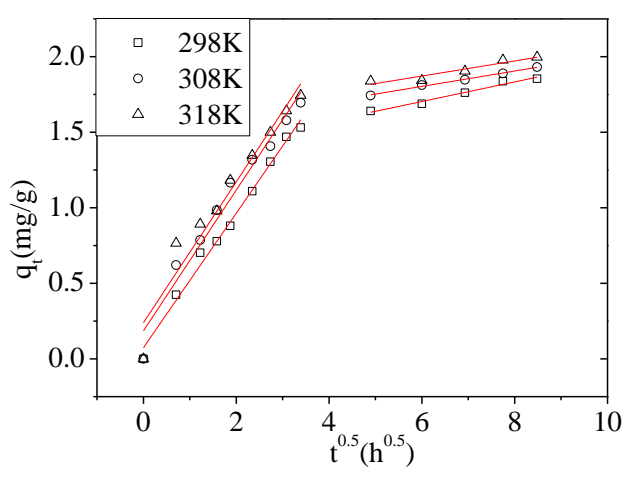

(b)

Figure 5. Effect of different temperatures on $\mathrm{As}(\mathrm{V})$ adsorption. (a) Effect of the temperature on the $\mathrm{As}(\mathrm{V})$ removal rate as a function of time. (b) Intraparticle diffusion model fit for the $\mathrm{As}(\mathrm{V})$ removal by NZVI/AC at different temperatures (conditions: $C_{0}=2.0 \mathrm{mg} / \mathrm{L}, \mathrm{pH}=6.5,150 \mathrm{rpm}, 20 \times 40$ mesh particle size, adsorbent dosage $=1.5 \mathrm{~g} / \mathrm{L}, t=72 \mathrm{~h}, \mathrm{~T}=298,308,318 \mathrm{~K})$.

Table 5. Rate constants for the kinetic model of As(V) adsorption on NZVI/AC at different temperatures.

\begin{tabular}{ccccc}
\hline \multirow{2}{*}{ Parameter } & \multicolumn{4}{c}{ Weber-Morris Diffusion } \\
\cline { 2 - 5 } & \multicolumn{3}{c}{ 1st Step } & \multicolumn{3}{c}{ 2nd Step } \\
\hline T(K) & $k_{i d \mathbf{1}}$ & $\mathbf{R}^{\mathbf{2}}$ & $\boldsymbol{k}_{\boldsymbol{i d \mathbf { 2 }}}$ & $\mathbf{R}^{\mathbf{2}}$ \\
\hline 298 & 0.4449 & 0.9900 & 0.0647 & 0.9673 \\
308 & 0.4657 & 0.9677 & 0.0203 & 0.9926 \\
318 & 0.4664 & 0.9503 & 0.0283 & 0.8860 \\
\hline
\end{tabular}

The adsorption of $\mathrm{As}(\mathrm{V})$ onto NZVI/AC showed slower kinetics compared with NZVI. More than $80 \%$ of the $\mathrm{As}(\mathrm{V})$ was removed by NZVI within $7 \mathrm{~min}$ and $\sim 99.9 \%$ was removed within $60 \mathrm{~min}$ [28]. $\mathrm{As}(\mathrm{V})$ adsorption on NZVI particles located inside AC macro-pores or -channels was slowed down by the carrier. However, NZVI possessing a tiny particle size displayed more $\mathrm{As}(\mathrm{V})$ adsorption due to its greater surface area.

Although the kinetics of $\mathrm{As}(\mathrm{V})$ adsorption by NZVI/AC was slower than by NZVI, loading NZVI with AC has several advantages, including (1) NZVI/AC avoids ferric loss, condensation, and further separation from the water system, thereby reducing water treatment costs; (2) NZVI/AC exhibits attrition resistance properties and excellent mechanical strength; and (3) NZVI/AC shows high recyclability and could sustain $\mathrm{As}(\mathrm{V})$ removal activity even after eight regeneration cycles. 
In summary, optimal conditions for the removal of $\mathrm{As}(\mathrm{V})$ from aqueous solutions were found to be $318 \mathrm{~K}, \mathrm{pH} 3.5,1.5 \mathrm{~g} / \mathrm{L}$ adsorbent mass, and $72 \mathrm{~h}$ equilibrium time.

\subsection{As $(V)$ Adsorption in the Presence of Other Ions}

\subsubsection{Effect of Single Coexisting Ions on Adsorption Kinetics}

Drinking water sources are likely to contain several ions that might compete with As for the applicable adsorption sites on NZVI/AC. The effects of coexisting ions on As(V) removal depend on their type and concentration. Here, we probed the effects of $\mathrm{PO}_{4}^{3-}$ and $\mathrm{SiO}_{4}^{2-}$ as interfering ions because they are frequently found in groundwater streams and might either inhibit or enhance As(V) removal kinetics (Figure 6).

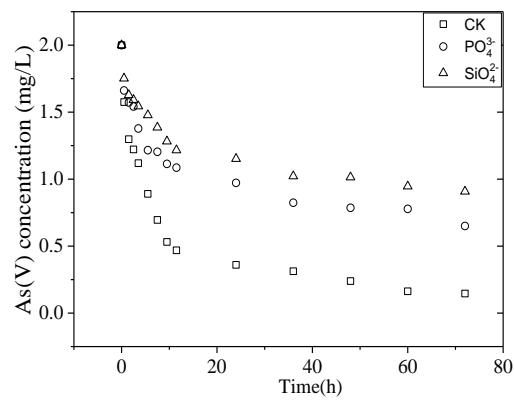

(a)

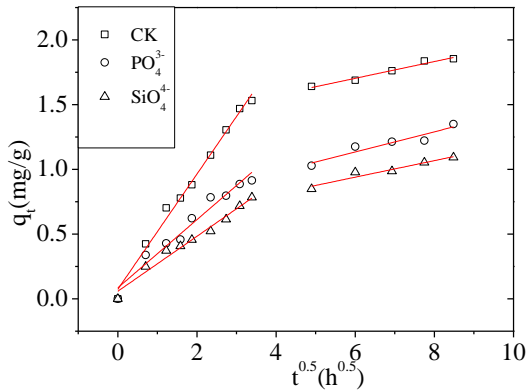

(b)

Figure 6. Effect of single interfering ions on $\mathrm{As}(\mathrm{V})$ adsorption. (a) Effect of single coexisting ions on $\mathrm{As}(\mathrm{V})$ removal as a function of time. (b) Intraparticle diffusion model fit for the As $(\mathrm{V})$ removal by $\mathrm{NZVI} / \mathrm{AC}$ in the presence of single coexisting ions (conditions: $C_{0}=2.0 \mathrm{mg} / \mathrm{L}, 150 \mathrm{rpm}, 20 \times 40 \mathrm{mesh}$ particle size, $t=72 \mathrm{~h}, \mathrm{~T}=298 \mathrm{~K}$, adsorbent dosage $=1.5 \mathrm{~g} / \mathrm{L}, \mathrm{pH}=6.5$, coexisting ions $=\mathrm{PO}_{4}^{3-}$ or $\mathrm{SiO}_{4}^{2-}$ ).

$\mathrm{CK}$, control in the absence of interfering ions.

Several studies have shown that $\mathrm{PO}_{4}^{3-}$ and $\mathrm{SiO}_{4}^{2-}$ inhibit $\mathrm{As}(\mathrm{V})$ removal $[19,25,26,28,29]$. In our study, the $k_{i d 1}$ of $k_{\mathrm{p}}$ and $k_{\mathrm{si}}$ decreased to $59.2 \%$ and $47.7 \%$, respectively, compared with the control (Table 6). The As(V), $\mathrm{PO}_{4}^{3-}$, and $\mathrm{SiO}_{4}^{2-}$ are all tetrahedral anions and generate inner-sphere complexes with the effective functional groups at the surface of iron oxides. Competition for adsorption sites reduces the adsorption of either negative ion when both are present compared with either single anion. Likewise, $\mathrm{ZNVI} / \mathrm{AC}$ acted as a positive adsorbent for both $\mathrm{PO}_{4}^{3-}$ and $\mathrm{SiO}_{4}^{2-}$ and the presence of either one in excess concentration over $\mathrm{As}(\mathrm{V})$ in groundwater would cause imperfect removal of As(V). Alternatively, an excess of ZNVI/AC may be used to assure the complete removal of As(V) in the presence of strong competing anions [30].

Table 6. Rate constants for the kinetic model of $\mathrm{As}(\mathrm{V})$ adsorption on NZVI/AC in the presence of single coexisting ions.

\begin{tabular}{ccccc}
\hline \multirow{2}{*}{ Parameter } & \multicolumn{3}{c}{ Weber-Morris Diffusion } \\
\cline { 2 - 5 } & \multicolumn{2}{c}{ 1st Step } & \multicolumn{2}{c}{ 2nd Step } \\
\hline Single Coexisting Ions & $\boldsymbol{k}_{\boldsymbol{i d} \mathbf{1}}$ & $\mathbf{R}^{\mathbf{2}}$ & $\boldsymbol{k}_{\boldsymbol{i d} \mathbf{2}}$ \\
\hline $\mathrm{CK}^{1}$ & 0.4449 & 0.9900 & 0.0647 & 0.9673 \\
$\mathrm{PO}_{4}^{3-}$ & 0.2633 & 0.9577 & 0.0776 & 0.8741 \\
$\mathrm{SiO}_{4}^{2-}$ & 0.2123 & 0.9756 & 0.0638 & 0.9180 \\
\hline
\end{tabular}

${ }^{1} \mathrm{CK}=$ control check. 


\subsubsection{Multiple Coexisting Ion Effect on Adsorption Kinetics}

The above results described the effect of single commonly coexisting ions on the adsorption kinetics of $\mathrm{As}(\mathrm{V})$. However, groundwater contains many coexisting ions simultaneously.

Therefore, we next studied the effect of multiple simultaneously coexisting ions and raw groundwater on $\mathrm{As}(\mathrm{V})$ removal (The raw ground-water quality parameters see Table 1$)$. The $\mathrm{As}(\mathrm{V})$ removal rate in simulated groundwater containing multiple coexisting ions was only $41.7 \%$, while, in the control check water (containing only $\mathrm{As}(\mathrm{V})$ ) the removal rate was $92.7 \%$ (Figure 7 ). In order to meet the Chinese drinking water standard (GB 5794-2006: As(V) $\leq 0.01 \mathrm{mg} / \mathrm{L}$ ), the adsorbent dosage needed a two-fold increase $(4.5 \mathrm{~g} / \mathrm{mL})$ for purifying raw groundwater. $\mathrm{As}(\mathrm{V})$ removal rate from the simulated water and raw groundwater was $\geq 99.9 \%$ in both cases (Figure 8 ).

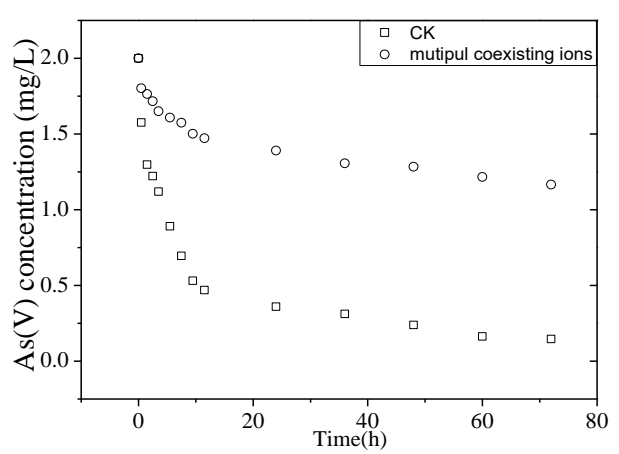

(a)

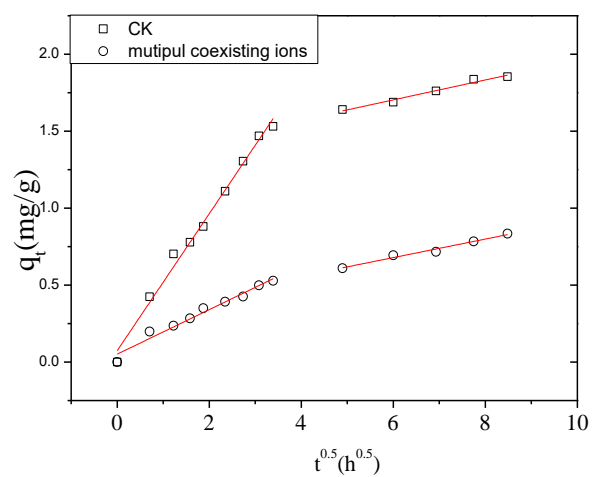

(b)

Figure 7. Effect of multiple interfering ions on $\mathrm{As}(\mathrm{V})$ adsorption. (a) Effect of multiple coexisting ions on the removal of $\mathrm{As}(\mathrm{V})$ as a function of time. (b) Intraparticle diffusion model fit for the removal of $\mathrm{As}(\mathrm{V})$ by NZVI/AC in the presence of multiple interfering ions (conditions: $C_{0}=2.0 \mathrm{mg} / \mathrm{L}, 150 \mathrm{rpm}$, $20 \times 40$ mesh particle size, $t=72 \mathrm{~h}, \mathrm{~T}=298 \mathrm{~K}$, adsorbent dosage $=1.5 \mathrm{~g} / \mathrm{L}, \mathrm{pH}=7.58$ (i.e., natural $\mathrm{pH}$ ), coexisting ions $=\mathrm{PO}_{4}^{3-}, \mathrm{SiO}_{4}^{2-}$ ).

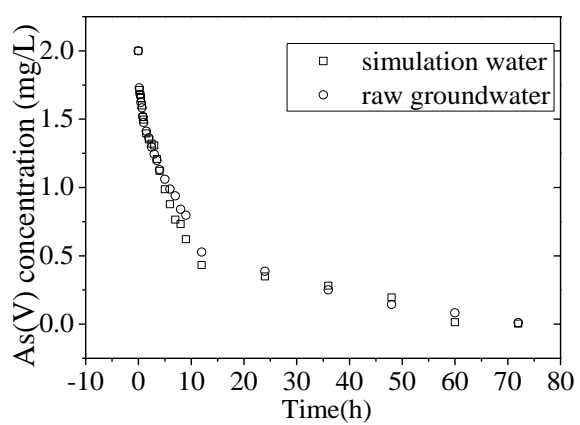

(a)

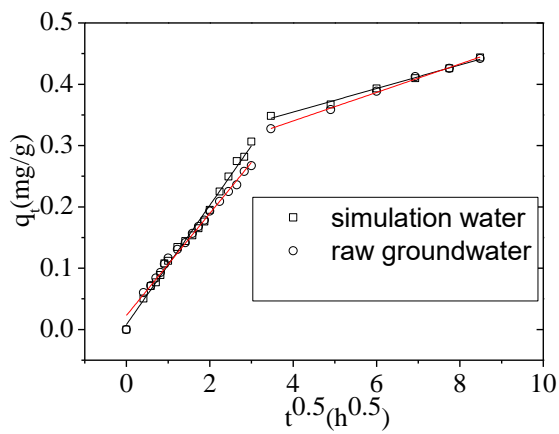

(b)

Figure 8. Adsorption of $\mathrm{As}(\mathrm{V})$ from raw groundwater. (a) Performance of NZVI/AC in the removal of $\mathrm{As}(\mathrm{V})$ from raw groundwater compared with water containing only $\mathrm{As}(\mathrm{V})$. (b) Intraparticle diffusion model fit for the As $(\mathrm{V})$ removal by NZVI/AC in raw groundwater compared to simulation water containing only $\mathrm{As}(\mathrm{V})$ (conditions: $C_{0}=2.0 \mathrm{mg} / \mathrm{L}, 150 \mathrm{rpm}, 20 \times 40$ mesh particle size, $t=72 \mathrm{~h}, \mathrm{~T}=298 \mathrm{~K}$, adsorbent dosage $=4.5 \mathrm{~g} / \mathrm{L}, \mathrm{pH}=6.5$ ).

The adsorption kinetics of $\mathrm{As}(\mathrm{V})$ in the simulated groundwater containing multiple coexisting ions was slower than in water containing single coexisting ions (Tables 7 and 8 ). 
Table 7. The adsorption kinetic model rate constants for the As (V) on NZVI/AC in the presence of multiple coexisting ions.

\begin{tabular}{ccccc}
\hline \multirow{2}{*}{ Parameter } & \multicolumn{3}{c}{ Weber-Morris Diffusion } \\
\cline { 2 - 5 } & \multicolumn{2}{c}{ 1st Step } & \multicolumn{2}{c}{ 2nd Step } \\
\hline Multiple Coexisting Ions & $\boldsymbol{k}_{\boldsymbol{i d} \mathbf{1}}$ & $\mathbf{R}^{\mathbf{2}}$ & $\boldsymbol{k}_{\boldsymbol{i d} \mathbf{2}}$ & $\mathbf{R}^{\mathbf{2}}$ \\
\hline CK & 0.4449 & 0.9900 & 0.0648 & 0.9673 \\
multiple coexisting ions & 0.1447 & 0.9679 & 0.0602 & 0.9722 \\
\hline
\end{tabular}

Table 8. Rate constants for the kinetic model of $\mathrm{As}(\mathrm{V})$ adsorption on NZVI/AC. Comparison of simulation water containing only $\mathrm{As}(\mathrm{V})$ vs. raw groundwater.

\begin{tabular}{|c|c|c|c|c|}
\hline \multirow{3}{*}{ Parameter } & \multicolumn{4}{|c|}{ Weber-Morris Diffusion } \\
\hline & \multicolumn{2}{|c|}{ 1st Step } & \multicolumn{2}{|c|}{ 2nd Step } \\
\hline & $k_{i d 1}$ & $R^{2}$ & $k_{i d 2}$ & $R^{2}$ \\
\hline simulation water & 0.09725 & 0.9922 & 0.01922 & 0.9907 \\
\hline raw groundwater & 0.0832 & 0.9902 & 0.02323 & 0.9952 \\
\hline
\end{tabular}

$\mathrm{As}(\mathrm{V})$ was adsorbed as an inner sphere complex on iron oxyhydroxides which corroded from NZVI/AC in other previous studies. Phosphorus and arsenic belong to VA and have similar atomic structures and chemical properties, sharing the same outer shell of $\mathrm{s}^{2} \mathrm{p}^{3}$ [26]. Both phosphate and silicate bonded with iron hydroxides and competed for adsorption sites with arsenic. They would compete for similar adsorptive binding sites, hence decreasing the removal rate of arsenic [13]. The reduction in available adsorption sites would weaken the adsorption rate and adsorption capacity of NZVI/AC [19]. This may be attributed to a decrease in adsorbent pores, surface area, the number of unsaturated sites, and active sites [31]. In addition, the radius of $\mathrm{P} / \mathrm{As}$ anions is similar, which respectively 0.248 , $0.238 \mathrm{~nm}$. Isomorphous replacement occurs when different ions yield slightly soluble crystals in a similar geometric form. Therefore, the $\mathrm{PO}_{4}^{3-}$ substitution of $\mathrm{AsO}_{4}^{3-}$ in the $\mathrm{NZVI/AC}$, which decreased the adsorption kinetics, too [32].

\section{Conclusions}

The adsorption kinetics $k_{i d 1}$ of the $\mathrm{As}(\mathrm{V})$ increased from 0.1224 to 0.5251 with increasing initial $\mathrm{As}(\mathrm{V})$ concentration from 0.5 to $4.0 \mathrm{mg} / \mathrm{L}$. However, the $k_{i d 1}$ decreases from 0.4921 to 0.1654 when the $\mathrm{pH}$ increases from 3.5 to 9.5 , and when the adsorbent dosages increase from 0.5 to $2.0 \mathrm{~g} / \mathrm{L}$, the $k_{i d 1}$ decreases from 0.5515 to 0.2482 . The kinetics of the $\mathrm{As}(\mathrm{V})$ adsorption to NZVI/AC in the simulated groundwater containing single or multiple coexisting ions was slower by about 1 and 3 times than for the simulated groundwater without coexisting ions. We found that intraparticle diffusion exhibited the rate-determining effects on the $\mathrm{As}(\mathrm{V})$ removal process which resulted from the relatively simple macropore structure of the NZVI/AC. The results of the present investigation indicate that NZVI/AC is a promising $\mathrm{As}(\mathrm{V})$ remover. The NZVI/AC adsorbent does not share the disadvantages of other nano-iron particles that readily agglomerate, and NZVI/AC is easily separated from the water. Further work is required to determine if NZVI/AC can be applied for the removal of other harmful components in water.

Author Contributions: Conceptualization, H.Z.; investigation, H.Z. and M.S.; Methodology X.Z. and D.Y.; resources X.Z. and D.Y.; writing-original draft preparation, H.Z. and M.S.; writing-review and editing, B.L.; supervision, B.L.; funding acquisition, H.Z. and M.S. All authors have read and agreed to the published version of the manuscript.

Funding: This research was funded by the National Nature Science Foundation of China, grant number $51709141 \& 400773076$. 
Acknowledgments: The support of this work by the National Nature Science Foundation of China (NSFC, 51709141\&400773076) is gratefully acknowledged.

Conflicts of Interest: The authors declare no conflict of interest.

\section{References}

1. Zou, Y.; Wang, X.; Khan, A. Environmental remediation and application of nanoscale zero-valent iron and its composites for the removal of heavy metal ions: A review. Environ. Sci. Technol. 2016, 50, 7290-7304. [CrossRef] [PubMed]

2. Tuček, J.; Prucek, R.; Kolařík, J. Zero-valent iron nanoparticles reduce arsenites and arsenates to As (0) firmly embedded in Core-Shell superstructure: Challenging strategy of arsenic treatment under anoxic conditions. ACS Sustain. Chem. Eng. 2017, 5, 3027-3038. [CrossRef]

3. Xu, J.; Cao, Z.; Zhang, Y. A review of functionalized carbon nanotubes and graphene for heavy metal adsorption from water: Preparation, application, and mechanism. Chemosphere 2018, 195, 351-364. [CrossRef]

4. Maiti, A.; Mishra, S.; Mohit Chaudhary, M. Nanoscale materials for arsenic removal from water. In Nanoscale Materials in Water Purification; Elsevier: Amsterdam, The Netherlands, 2019; pp. 707-733.

5. Shang, J.; Zong, M.; Yu, Y. Removal of chromium (VI) from water using nanoscale zerovalent iron particles supported on herb-residue biochar. J. Environ. Manag. 2017, 197, 331-337. [CrossRef]

6. Shi, L.; Zhou, Y.; Chen, Z. Simultaneous adsorption and degradation of Zn2+ and Cu2+ from wastewaters using nanoscale zero-valent iron impregnated with clays. Environ. Sci. Pollut. Res. 2013, 20, 3639-3648. [CrossRef] [PubMed]

7. Kim, Y.; Kim, C.; Choi, I. Arsenic removal using mesoporous alumina prepared via a templating method. Environ. Sci. Technol. 2004, 38, 924-931. [CrossRef] [PubMed]

8. Penke, Y.K.; Anantharaman, G.; Ramkumar, J.; Kar, K.K. Redox synergistic Mn-Al-Fe and Cu-Al-Fe ternary metal oxide nano adsorbents for arsenic remediation with environmentally stable $\mathrm{As}(0)$ formation. J. Hazard. Mater. 2019, 364, 519-530. [CrossRef] [PubMed]

9. Wu, D.; Peng, S.; Yan, K. Enhanced As (III) sequestration using sulfide-modified nano-scale zero-valent iron with a characteristic core-shell structure: Sulfidation and as distribution. ACS Sustain. Chem. Eng. 2018, 6, 3039-3048. [CrossRef]

10. Jain, A.; Agarwal, M. Synthesising zero valent iron supported on alumina for removal of arsenic from drinking water. Interdiscip. Environ. Rev. 2017, 18, 108-123. [CrossRef]

11. Tan, G.; Mao, Y.; Wang, H. Comparison of biochar- and activated carbon-supported zerovalent iron for the removal of $\mathrm{Se}(\mathrm{IV})$ and $\mathrm{Se}(\mathrm{VI})$ : Influence of $\mathrm{pH}$, ionic strength, and natural organic matter. Environ. Sci. Pollut. Res. 2019, 26, 21609-21618. [CrossRef]

12. Zhu, H.; Jia, Y.; Wu, X. Removal of arsenic from water by supported nano zero-valent iron on activated carbon. J. Hazard. Mater. 2009, 172, 1591-1596. [CrossRef] [PubMed]

13. Jia, Y.; Demopoulos, G.P. Adsorption of arsenate onto ferrihydrite from aqueous solution: Influence of media (sulfate vs. nitrate), added gypsum, and pH alteration. Environ. Sci. Technol. 2005, 39, 9523-9527. [CrossRef] [PubMed]

14. Wang, S.; Gao, B.; Li, Y. Adsorptive removal of arsenate from aqueous solutions by biochar supported zero-valent iron nanocomposite: Batch and continuous flow tests. J. Hazard. Mater. 2017, 322, 172-181. [CrossRef] [PubMed]

15. Qiu, H.; Lv, L.; Pan, B.C. Critical review in adsorption kinetic models. J. Zhejiang Univ. Sci. A 2009, 10, 716-724. [CrossRef]

16. Largitte, L.; Pasquier, R. A review of the kinetics adsorption models and their application to the adsorption of lead by an activated carbon. Chem. Eng. Res. Des. 2016, 109, 495-504. [CrossRef]

17. Gupta, S.S.; Bhattacharyya, K.G. Kinetics of adsorption of metal ions on inorganic materials: A review. Adv. Colloid Interface Sci. 2011, 162, 39-58. [CrossRef]

18. Lackovic, J.A.; Nikolaidis, N.P.; Dobbs, G.M. Inorganic arsenic removal by zero-valent iron. Environ. Eng. Sci. 2000, 17, 29-39. [CrossRef]

19. Kanel, S.R.; Grenèche, J.M.; Choi, H. Arsenic(V) removal from groundwater using nano scale zero-valent iron as a colloidal reactive barrier material. Environ. Sci. Technol. 2006, 40, 2045-2050. [CrossRef] 
20. Juang, R.S.; Tseng, R.L.; Wu, F.C. Adsorption behavior of reactive dyes from aqueous solutions on chitosan. J. Chem. Technol. Biotechnol. Int. Res. Process. Clean. Technol. 1997, 70, 391-399. [CrossRef]

21. Oke, I.A.; Olarinoye, N.O.; Adewusi, S.R.A. Adsorption kinetics for arsenic removal from aqueous solutions by untreated powdered eggshell. Adsorption 2008, 14, 73-83. [CrossRef]

22. Doke, K.M.; Khan, E.M. Equilibrium, kinetic and diffusion mechanism of $\mathrm{Cr}(\mathrm{VI})$ adsorption onto activated carbon derived from wood apple shell. Arab. J. Chem. 2017, 10, S252-S260. [CrossRef]

23. Hameed, B.H.; Ahmad, A.A.; Aziz, N. Isotherms, kinetics and thermodynamics of acid dye adsorption on activated palm ash. Chem. Eng. J. 2007, 133, 195-203. [CrossRef]

24. Ong, S.A.; Seng, C.E.; Lim, P. Kinetics of adsorption of $\mathrm{Cu}$ (II) and Cd (II) from aqueous solution on rice husk and modified rice husk. Electron. J. Environ. Agric. Food Chem. 2007, 6, 1764-1774.

25. Raven, K.P.; Jain, A.; Loeppert, R.H. Arsenite and arsenate adsorption on ferrihydrite: Kinetics, equilibrium, and adsorption envelopes. Environ. Sci. Technol. 1998, 32, 344-349. [CrossRef]

26. Guo, X.; Chen, F. Removal of arsenic by bead cellulose loaded with iron oxyhydroxide from groundwater. Environ. Sci. Technol. 2005, 39, 6808-6818. [CrossRef]

27. Hamadi, N.K.; Chen, X.D.; Farid, M.M. Adsorption kinetics for the removal of chromium(VI) from aqueous solution by adsorbents derived from used tyres and sawdust. Chem. Eng. J. 2001, 84, 95-105. [CrossRef]

28. Kanel, S.R.; Manning, B.; Charlet, L. Removal of arsenic (III) from groundwater by nanoscale zero-valent iron. Environ. Sci. Technol. 2005, 39, 1291-1298. [CrossRef]

29. Su, C.; Puls, R.W. Arsenate and arsenite removal by zerovalent iron: Effects of phosphate, silicate, carbonate, borate, sulfate, chromate, molybdate, and nitrate, relative to chloride. Environ. Sci. Technol. 2001, 35, 4562-4568. [CrossRef]

30. Taty-Costodes, V.C.; Fauduet, H.; Porte, C. Removal of Cd (II) and Pb (II) ions, from aqueous solutions, by adsorption onto sawdust of Pinus sylvestris. J. Hazard. Mater. 2003, 105, 121-142. [CrossRef]

31. Ali, R.M.; Hamad, H.A.; Hussein, M.M. Potential of using green adsorbent of heavy metal removal from aqueous solutions: Adsorption kinetics, isotherm, thermodynamic, mechanism and economic analysis. Ecol. Eng. 2016, 91, 317-332. [CrossRef]

32. Georgopoulou, A.N.; Adam, R.; Raptopoulou, C.P. Isomorphous replacement of M(II) ions in M(II)-Gd(III) dimers $(\mathrm{M}(\mathrm{II})=\mathrm{Cu}(\mathrm{II}), \mathrm{Mn}(\mathrm{II}), \mathrm{Ni}(\mathrm{II}), \mathrm{Co}(\mathrm{II}), \mathrm{Zn}(\mathrm{II}))$ : Magnetic studies of the products. Dalton Trans. 2010, 39, 5020-5027. [CrossRef] [PubMed] 